\title{
Factors Affecting User's Intention to Adopt Smart Home in Malaysia
}

https://doi.org/10.3991/ijim.v13i12.11083

Ng Tee Wei, Ahmad Suhaimi Baharudin,

Lubna A. Hussein ${ }^{(凶)}$, Mohd Faiz Hilmi

Universiti Sains Malaysia, Penang, Malaysia

lubnafatlawi@gmail.com

\begin{abstract}
Nowadays, the advancement of technology makes life easier and convenient. The smart home is one of the technology provides a better living environment for the residents. The purpose of this study is to make a systematic and empirical study on the factors and model that influencing the intention to adopt smart home in Malaysia. Clear interface, consistency, attractiveness, information accuracy, information completeness, perceived security and perceived privacy used as the variables to investigate the intention to adopt the smart home. The quantitative method was used in this research. The sample size of this research is 102 respondents. The questionnaire was used for data collection. From the statistical analysis, the result verifies that clear interface, consistency, attractiveness, information accuracy, perceived security, and perceived privacy have positive impact on the Malaysia householder's intention to adopt the smart home. By referring to this, the practitioner can refer and focus on those variables to develop the smart home that suitable for Malaysian.
\end{abstract}

Keywords - TAM model, Perceived usefulness, Perceived ease of use, Smart Home Technology.

\section{$1 \quad$ Introduction}

A smart home can defined as a residence equipped with a communication network, high-tech household devices, appliances, and sensors that can be remotely accessed, monitored, and controlled and that provide services responding to the residents' needs [1] [2].

The smart home technology existed as concepts for many years but its increases gets attention by the public over the last decade. It seemed very futuristic at the beginning of introducing smart home and it seemed unthinkable to program and remotely control from long distance to operate appliances in the smart home [3]. Smart home now becomes a reality and it can monitor and operate the home appliance and others by using a mobile phone from a long distance [4]. For example, residents can switch on the air conditioning before they reach home by using their mobile phones. This means that smart home services are a set of technologies that provide human-oriented networking environments for connecting equipment and applications in the house [5]. 
The home appliances in "traditional home" able to operate locally and manually with flip or switch on the button. On the other hand, the smart home can be remote the electronic control and manage the smart appliances from long distances.

The continuous advancement of smart home technology has brought many innumerable advantages to the lifestyle. Due to the advancement of technology, smart homes become smarter with different usage compare to the initial ideas. The real-time remote control feature of a smart home can provide better energy management options and provides equal benefits for people of all ages. Therefore, there is a lot of different requirements and usage that are interesting by the public such as indoor convenience, security, energy or resource management, pet monitoring, and others.

Despite the positive benefits of Smart Home, and its emerging market opportunities, evidence has shown that its rate of adoption among individual users is generally low, especially in developing countries of Asia such as Malaysia, Singapore, China, South Korea, Thailand, and Indonesia [6, 7]. According to Statista, Malaysia only has $1.4 \%$ penetration in the smart home among 50 of the world's leading digital economies during 2017, In contrast to that, the US penetration was $26.5 \%$ in 2017 [8]. Therefore, Malaysia considered very low adoption rate compare with the US.

\section{$2 \quad$ Literature Review}

To the best of our understanding, was the study of smart home services in Taiwan. In this study, the smart home services have been developed by related firms and have had a strong impact on consumers' lives. This research integrates involvement antecedents, innovation diffusion factors and a technology acceptance model to develop a conceptual framework for discussing consumer attitudes and adoption behaviors toward smart home service applications [9].

Another important study was mentioned to the factors, as well as their interrelationships, influencing senior citizens to adopt elderly-friendly the smart home technology that supports ageing-in-place in high-density Hong Kong living settings [10]. In Vietnams, the study was developed a comprehensive research model that can explain potential customer's behavioral intentions to adopt and use smart home services in Vietnams and determine which key factors affect the intention [11].

In UK, the study was explored the barriers of smart home adoption. Using workshops and expert interviews, they built a framework classifying drivers and barriers of smart homes adoption into being technical, economic, commercial, or policy related [1].

For the study of smart home technology in the context of households, research is still in its early phases [12]. The absence of studies dealing with the system aspect variables is also important criteria that can be used to enhance the system for better acceptance by the user. Therefore, this study aims to identify the factors that influence Malaysia consumer intention to adopt smart home technology by combining system variables and non-system variables as the model in order to improve the system and adoption rate of smart home in Malaysia. 


\section{$3 \quad$ Theoretical Background}

\subsection{Technology acceptance model}

Among the many theoretical models for explaining the adoption of particular systems or services, the TAM proposed by Davis is one of the most widely used frameworks [13]. TAM has been validated as a useful theoretical model for exploring information-oriented or smart services. For example, [14] used TAM to make clear the intention to use smartphone devices and confirmed the validation of the original TAM with self-efficacy as a notable determinant. Lai [15] introduced a revised TAM with the concept of reliability (trust) for examining the users' intention to use smart sharing systems and examined how developers and manufacturers improve their systems.

The study [5] was once used Value-based Adoption Model (VAM) to conduct a lookup about the adoption of IoT (Internet of Things) in smart home service. This finding used VAM, which associated with the variable of TAM and Elaboration Likelihood Model (ELM). The perceived sacrifice and perceived benefits have been used as the variables to test the intention to use. The variable of privacy risk labeled into perceived sacrifice whilst perceived usefulness categorized into perceived benefits. According to the findings, it indicates that each perceived sacrifice and perceived benefit is a significant effect on perceived value and indirectly significant impact on the intention to use.

In Germany [16], the researchers combined TAM model, Innovation diffusion theory and risk theory to determine the important factors affect the smart home intention adopt. The finding for the study found that the most important determinants of use intention are compatibility and usefulness of the application.

Based on research mentioned earlier, the determinants of consumer intention to adopt smart home can be listed which are perceived ease of use, perceived usefulness, and privacy risk. In order to focus on system variables, the system variables that categorized in ease of use and usefulness were determined. For this study, perceived the privacy and perceived security were adding, because of these are important factors that determines either positive or negative attitude of users towards IT adoption. Evidence has shown that consumers are adverse to accepting or to using technology without first establishing that the issue of security and privacy is well addressed [6, 17].

\subsection{Research model}

Prior TAM research has demonstrated that perceived ease of use and perceived usefulness are critical factors in predicting the acceptance and use of new technologies [18, 19, and 20]. Many researches showed that perceived usefulness and ease of use influenced the ways users accept a new innovation or system. Although there is a criticism about TAM model and its derivatives for their divergent and contradictory results the TAM model has confirmed its utility in contributing to the grasp and explanation of intention to use at some stage in technological implementations [21]. 
Therefore, TAM is a fabulous approach to reading the acceptance of smart home adoption. It approves us to orient subsequent interventions and to extend the dimensions for perceived usefulness and perceived ease of use, in our case for use of smart home and has allowed us to better contextualize TAM and the intentions to use that ensued.

TAM model was use to present research aims for this study. This research aims to explain the influential factors of consumer intent to adopt smart home technology are as below:

- This research is to propose a research model for user intention to adopt the smart home technology

- This research is to investigate the relationship of clear interface, consistency, attractiveness, information accuracy, information completeness, perceived security and perceived privacy with the consumer intention to adopt the smart home technology. The Fig. 1 shows the proposed conceptual framework that used to investigate the user intention to adopt smart home in Malaysia 


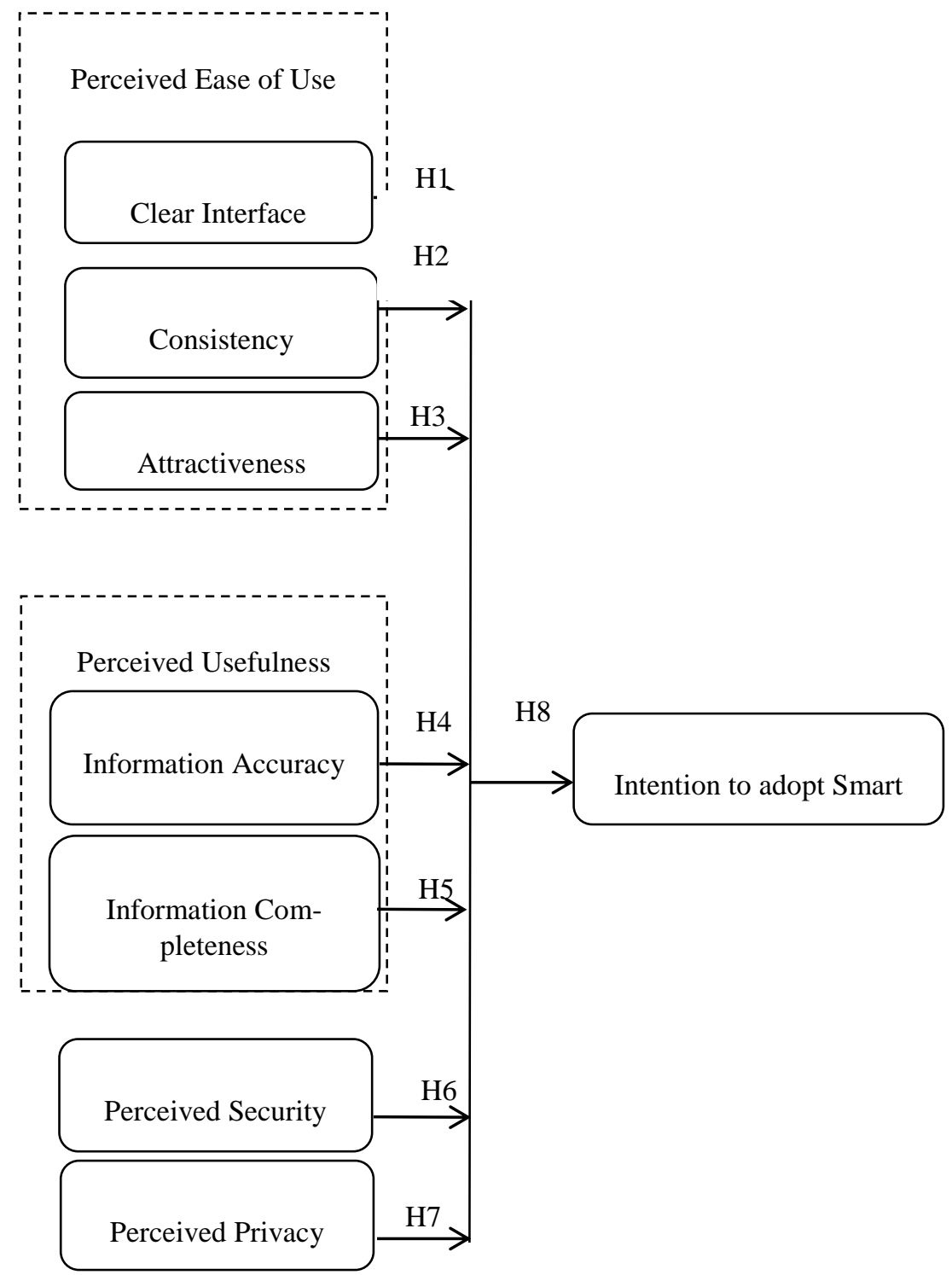

Fig. 1. The Proposed Conceptual Framework and Hypothesis

\subsection{Hypothesis development}

The factors that used in this study are explained below:

Perceived ease of use is the degree of user expects the system to be free of effort [13]. Based on TAM, perceived ease of use is an important variable to determine the 
intention of the user to use the technology. In this study, there are three items categorized in perceived ease of use that is clear interface, consistency, and attractiveness.

- Clear interface refers to the system interface should be clear, understandable and simple. All the interface elements such as icon or button should provide clear meaning to the user, which can help the user save the time to understanding the meaning of each element. The clear interface defined as one of the determinants to investigate the intention of householders to use the smart home system because the smart home system with a clear interface can make the system more comfortable and easy to use.

- Consistency of the system refers to the system should provide standard design such as naming, formats, button location, language, icon and other elements among the system. In this study, the smart home technology can monitor and operate through a smartphone application, which has different modules or functions. The intuitive and consistent of the application interface is important criteria, which can affect the intention of the user to adopt it. As long as the user feel that the system displays in a consistent way, it can help them to understand quickly and feel comfortable when using it, the smart home system is perceived as easy to use.

- Attractiveness of the system refers to the perception of how the system looks that can attract the intention of the user. The good system should not only simple and easy to use but the attractiveness of the system important to gain the attention of the user. Attractiveness can be defined as the term of graphical, color, light, contrast and texture that display on the system screen [22]. Therefore, this study applies the clear interface, consistency and attractiveness to investigate how it will affect user intention to use the smart home technology.

H1: The clear interface has a positive impact on the user intention to adopt smart home technology.

$\mathrm{H} 2$ : The consistency has a positive impact on the user intention to adopt smart home technology.

H3: The attractiveness has a positive impact on the user intention to adopt smart home technology.

Perceived usefulness is the degree to this the perception of user believes that the system is useful and enhance their job performance [13].

- Information accuracy refer to the system should display the value that are accurate and same with the actual value. In this study, it refers to the in-formation shows on the system must accurate and correct as what shows in the smart home devices or appliances. For example, the cooling level of the air conditioner must same with what it shows in the smart home technology. For this study, the accuracy of the information provided by system can lead the user control or operate the smart home correctly, the system is perceived as usefulness.

- Information completeness refers to the system should provide complete and relevant information to the user. In other words, the necessary information for the system must be able to display to the user which is relevant to the running task. For 
example, the necessary information of fans such as number or location must show when the user trying to switch off the fan in the living room by using the system.

Therefore, this study applies the information accuracy and information completeness to investigate how it will affect user intention to use the smart home technology.

H4: The Information accuracy has a positive impact on the user intention to adopt smart home technology.

H5: The Information completeness has a positive impact on the user intention to adopt smart home technology.

Perceived security refers to the perception of consumer's transmission data are protected from risks related to security [23]. The security represents the degree of feeling safe when transferring the information through the network. Therefore, based on the evidence from previous studies on perceived security [6, 23] and [24], this study proposes the following hypothesis:

H6: The perceived security has a positive impact on the user intention to adopt smart home technology.

Perceived privacy refers to the perception of consumer's personal data are protected from risks related to privacy [23]. The privacy is important to the IT technology especially Smart home because the flow of information is transmitting over the internet that has the possibility of exposing the user private information [6]. This study proposes the following hypothesis:

H7: The perceived privacy has a positive impact on the user intention to adopt smart home technology.

The multiple hypotheses as follow:

H8: The clear interface, consistency, attractiveness, information accuracy, information completeness, perceived security, perceived privacy have positive impact on the user intention to adopt smart home technology.

\section{Methodology}

This study is to look at the factors that affect the user intention to adopt the smart home technology. The quantitative research method conducted in order to look at the factors. Quantitative research is described as a research that includes the use questionnaire in which the respondents' opinion is pre-determined. Quantitative research normally uses survey and experiments to collect the data. On the other hand, qualitative research is described as research that involves a collection of data by observing people [25]. Thus, a quantitative method was once employed in this research to reply the lookup questions. After the data is collected, the analysis method will be applied to test the records, which are correlations and multiple regression analysis.

\section{$5 \quad$ Instruments}

A questionnaire instrument was employed in the current research and is adapted using the conceptualization and development work found in smart homes literature. 
There are total of 32 questions used for the study with using seven-point Likert Scale ranging from one (strongly disagree) to seven (strongly agree).

Measurements for this research model are to apply the model used by previous research which is TAM. The items used for measuring are the clear interface $(\mathrm{CI})$, consistency (C), attractiveness (ATT), information accuracy (IA), information completeness (IC), perceived security (PS) and perceived privacy (PP). Six demographic variables were recorded: Know the smart home, gender, age, educational level, marital status, and Personal Income Level.

\section{Sample Characteristics}

The target respondents are Malaysia people who have the idea or knowledge about smart home how to use. This is because if the respondents don't know what smart home is, the designed questionnaire not suitable for them. Those respondents who know the smart home can give more accurate data and answer compare to those who doesn't know. To make sure all the respondents understand the questions, an example and explanation of the questions are prepared for respondents. Usability of the questionnaire is tested to make sure that the written format and suggested questions can be used before the manual questionnaire will be distributed for the respondents.

Convenience sampling and snowball sampling are used in this study because the targeted respondents have been acquired most conveniently or being distributed the survey questionnaire on a friend-to-friend basis. Snowball method has the advantage to have more potential to get the respondents in the targeted population [26].

The sample size for this study is stated according to [27], that the acceptable ratio is ten-to-one ratio of the independent variables. Therefore 7 independent variables used for this study and the minimum number of respondents are 70 respondents. However, because the time and resources is limited, the sample size of 102 is collected for this study.

\section{Data Analysis}

The data analysis and results by using Statistical Package of Social Science (SPSS), SPSS used to analyze the demographic analysis, descriptive statistics, reliability analysis, correlation analysis, and multiple regression analysis.

\subsection{Demographic variables}

The data is collected through distributing the questionnaires to the respondents whose know what is smart home. The data collected through face by face interaction with the respondents and send the e-survey form through email or social media to the respondents. There are total 150 questionnaires distributed but only 105 that have been responded. After the data filtering, there are only 102 data are valid for this research. In the demographic section of the questionnaires, there are total of 6 questions 
have to answer such as the smart home awareness, age, gender, marital status, education level and personal income level.

There are $(68 \%)$ male respondents and $(32 \%)$ female respondents. For the age group, the age range of $20-34$ years old is the largest part of the respondents with (34\%) respondents from the total of 102 respondents. The second higher age group is below 20 years old with total $(27 \%)$ respondents. While age group 35-49 years old represent by $(25 \%)$ respondents and there are only $(14 \%)$ respondents are representing by age group of above 50 years old. It shows that the younger generation located large part compare with elder generation. For the marital status, the result shows that (33\%) respondents are single and $(67 \%)$ of the respondents are married. The education level for the largest proportion of the respondents is Bachelor Degree level with (36\%) of the respondents. The second largest proportion is Diploma/STPM which represented by $(35 \%)$ respondents. There are $(16 \%)$ respondents are SPM level and $(13 \%)$ respondents are Master and above. The highest proportion for personal income level is rated at the income from $\$ 600-1200$ which represent by (39\%) of 102 respondents. The second higher proportion income is below $\$ 600$ with total $(30 \%)$ respondents, followed by income group \$1200-1800 with (20\%) respondents and the income group above $\$ 1800$ with $(11 \%)$.

\subsection{Reliability analysis}

The reliability for this study is using Cronbach's Alpha and the value should be equal or higher than 0.7 [28]. The higher Cronbach's Alpha value means the item are more reliable. Through the reliable analysis, it shows whether there is any item in the variables with Cronbach's Alpha value lower than 0.7. Based on the Cronbach's Alpha value of each of the variables shows in Table 1, all variables are accepted and reliable since the value greater than 0.7 .

Table 1. Reliable Analysis of the Variables

\begin{tabular}{|l|c|c|c|c|}
\hline \multicolumn{1}{|c|}{ Variable } & Items no. & $\begin{array}{c}\text { Corrected Item- } \\
\text { Total Correlation }\end{array}$ & $\begin{array}{c}\text { Cronbach's Alpha } \\
\text { if Item Deleted }\end{array}$ & $\begin{array}{c}\text { Cronbach's } \\
\text { Alpha }\end{array}$ \\
\hline Clear Interface & 4 & & & 0.83 \\
\hline CI1 & & 0.61 & 0.81 & \\
\hline CI2 & & 0.71 & 0.77 & \\
\hline CI3 & & 0.68 & 0.78 & \\
\hline CI4 & & 0.65 & 0.79 & 0.85 \\
\hline Consistency & 4 & & & \\
\hline C1 & & 0.71 & 0.81 & \\
\hline C2 & & 0.74 & 0.80 & \\
\hline C3 & & 0.66 & 0.83 & \\
\hline C4 & & 0.68 & 0.82 & \\
\hline Attractiveness & & & & \\
\hline ATT1 & 4 & 0.65 & 0.79 & \\
\hline ATT2 & & 0.72 & 0.76 & \\
\hline ATT3 & & 0.65 & 0.79 & \\
\hline ATT4 & & 0.62 & 0.80 & \\
\hline
\end{tabular}




\begin{tabular}{|c|c|c|c|c|}
\hline Information Accuracy & 4 & & & 0.86 \\
\hline IA1 & & 0.67 & 0.83 & \\
\hline IA2 & & 0.74 & 0.80 & \\
\hline IA3 & & 0.69 & 0.82 & \\
\hline IA4 & & 0.70 & 0.82 & \\
\hline Information Completeness & 4 & & & 0.89 \\
\hline IC1 & & 0.79 & 0.84 & \\
\hline IC2 & & 0.79 & 0.84 & \\
\hline IC3 & & 0.67 & 0.88 & \\
\hline IC4 & & 0.75 & 0.85 & \\
\hline Perceived Security & 4 & & & 0.82 \\
\hline PS1 & & 0.66 & 0.77 & \\
\hline PS2 & & 0.63 & 0.78 & \\
\hline PS3 & & 0.61 & 0.79 & \\
\hline PS4 & & 0.69 & 0.75 & \\
\hline Perceived Privacy & 4 & & & 0.84 \\
\hline PP1 & & 0.73 & 0.77 & \\
\hline PP2 & & 0.70 & 0.79 & \\
\hline PP3 & & 0.61 & 0.83 & \\
\hline $\mathrm{PP} 4$ & & 0.67 & 0.80 & \\
\hline Intention to use & 4 & & & 0.80 \\
\hline ITU1 & & 0.63 & 0.75 & \\
\hline ITU2 & & 0.61 & 0.75 & \\
\hline ITU3 & & 0.61 & 0.76 & \\
\hline ITU4 & & 0.63 & 0.74 & \\
\hline
\end{tabular}

\subsection{Descriptive analysis}

The purpose of descriptive analysis is used to quantitatively describe the collected information. It calculates and shows the mean, standard deviation, minimum and maximum of each variable [29]. The minimum represents the smallest value of the variable while maximum means the largest value. Mean refer to the measurement of the average value and standard deviation is the measurement of how the data set being spread. Table 2 shows the descriptive data of each variable.

Table 2. Descriptive Analysis

\begin{tabular}{|l|c|c|c|c|c|}
\hline & N & Min & Max & Mean & Std. Deviation \\
\hline Mean_CI & 102 & 3.75 & 6.50 & 5.42 & .61 \\
\hline Mean_C & 102 & 3.50 & 6.50 & 5.21 & .70 \\
\hline Mean_ATT & 102 & 3.00 & 6.50 & 5.03 & .63 \\
\hline Mean_IA & 102 & 4.00 & 6.50 & 5.40 & .62 \\
\hline Mean_IC & 102 & 3.00 & 6.25 & 5.04 & .78 \\
\hline Mean_PS & 102 & 4.00 & 6.50 & 5.40 & .61 \\
\hline Mean_PP & 102 & 3.75 & 6.50 & 5.26 & .60 \\
\hline Mean_ITU & 102 & 3.50 & 6.00 & 5.03 & .60 \\
\hline Valid N (listwise) & 102 & & & & \\
\hline
\end{tabular}


According the data shows in Table 2, the mean value of Clear Interface (CI), Information Accuracy (IA) and Perceived Security (PS) are close to each other with $5.42,5.40$, and 5.40 respectively. It means that most of the respondents agree that these 3 variables are very important and highly influencing their intention to adopt smart home technology. Besides that, perceived privacy (PP) and Consistency (C) also consider important to the respondents compare to the rest because its mean value are 5.26 and 5.21 respectively. While the Information Completeness (IC) and Attractiveness (ATT) is close to each other with 5.04 and 5.03 mean value respectively.

Therefore, the respondents feel that the information completeness and attractiveness is less important for them by comparing to others factors. Although the value of information completeness and attractiveness are lower than other but it also considered as an important factor to the respondents because its value is above 5 out of 7 point Likert scale. While the intention to use smart home among 102 respondents is rated at 5.03 which consider slightly agree that they have intention to use smart home.

\subsection{Correlation analysis}

Correlation analysis is used to show the positive or negative correlation and strength of the relationship among each variable. A positive correlation refer to the independent variable is directly proportional to dependent variable while negative correlation explain the independent variable is inversely proportional to the dependent variable [29]. In positive correlation means, the dependent variable will increase if independent variables increase, while dependent variable will decrease if independent variables increase in negative correlation. The strength of relationship can be determine by the correlation coefficient value, the value from 0.10 to 0.29 is weak, 0.30 to 0.49 consider moderate and 0.50 to 1.0 consider strong relationship [30].

The correlation of Clear Interface (CI), Consistency (C), Attractiveness (ATT), Information Accuracy (IA), Information Completeness (IC), Perceived Security (PS) and perceived privacy $(\mathrm{PP})$ are $0.950^{* *}, 0.963^{* *}, 0.893^{* *}, 0.963^{* *}, 0.692^{* *}, 0.967^{* *}$ and $0.940 * *$ respectively. All the variables with $* *$ represent the result of the variables in high level of confidence in this analysis because the significant value is less than 0.01 . Therefore, the variables have significant positive correlation with intention to use smart home.

\subsection{Multiple regression analysis}

Multiple regression analysis is used to identify the relation between single dependent variable and multiple independent variables. The below hypothesis is tested in multiple regression to determine the relationship of them. The Table 3 shows the results of the multiple regression analysis between all independent variables and intention to use.

H8: The clear interface, consistency, attractiveness, information accuracy, information completeness, perceived security, perceived privacy has positive impact on the user intention to adopt smart home technology. 
Table 3. Multiple Regression Analysis

\begin{tabular}{|l|c|c|c|l|}
\hline \multicolumn{1}{|c|}{ Independent variables } & $\begin{array}{c}\text { Item } \\
\text { Code }\end{array}$ & $\begin{array}{c}\text { Significant } \\
\text { value }\end{array}$ & $\begin{array}{c}\text { Adjusted R } \\
\text { Square }\end{array}$ & Standardized Coefficients \\
\hline & & 0.000 & 0.967 & \\
\hline Clear Interface & CI & & & $0.162(\mathrm{P}<0.01)$ Significant \\
\hline Consistency & C & & & $0.210(\mathrm{P}<0.05)$ Significant \\
\hline Attractiveness & ATT & & & $0.099(\mathrm{P}<0.05)$ Significant \\
\hline Information Accuracy & IA & & & $0.195(\mathrm{P}<0.01)$ Significant \\
\hline Information Completeness & IC & & Not significant \\
\hline Perceived Security & PS & & & $0.221(\mathrm{P}<0.05)$ Significant \\
\hline Perceived Privacy & PP & & & $0.141(\mathrm{P}<0.05)$ Significant \\
\hline
\end{tabular}

From the Table 3, the hypotheses of all independents variables are significant except information completeness because its significant value is greater than 0.1 . The significant value of clear interface, information accuracy and perceived security are $0.009,0.010$ and 0.007 respectively which less than 0.01 . While the consistency $(0.014)$, attractiveness (0.017) and perceived privacy (0.012) are less than 0.05 .

\section{Discussion of Findings}

Table 4 shows the result of finding among each variable. It shows that all independent variables are significant and positively impact the intention to adopt the smart home. For hypothesis 8 , it shows that the hypothesis only partial significant. During the hypothesis 8 testing in multiple regression analysis. The information completeness not significant to this study because the respondents feel the necessary information provided by the smart home system enough for them to operate it.

Table 4. Summary of Hypotheses

\begin{tabular}{|l|l|}
\hline \multicolumn{1}{|c|}{ Hypotheses } & Significance \\
\hline $\begin{array}{l}\text { H1: The clear interface has positive impact on the user intention to adopt smart home tech- } \\
\text { nology. }\end{array}$ & Accepted \\
\hline $\begin{array}{l}\text { H2: The consistency has positive impact on the user intention to adopt smart home technol- } \\
\text { ogy. }\end{array}$ & Accepted \\
\hline $\begin{array}{l}\text { H3: The attractiveness has positive impact on the user intention to adopt smart home tech- } \\
\text { nology. }\end{array}$ & Accepted \\
\hline $\begin{array}{l}\text { H4: The Information accuracy has positive impact on the user intention to adopt smart home } \\
\text { technology. }\end{array}$ & Accepted \\
\hline $\begin{array}{l}\text { H5: The Information completeness has positive impact on the user intention to adopt smart } \\
\text { home technology. }\end{array}$ & Accepted \\
\hline $\begin{array}{l}\text { H6: The perceived security has positive impact on the user intention to adopt smart home } \\
\text { technology. }\end{array}$ & Accepted \\
\hline $\begin{array}{l}\text { H7: The perceived privacy has positive impact on the user intention to adopt smart home } \\
\text { technology. }\end{array}$ & Accepted \\
\hline $\begin{array}{l}\text { H8: } \text { The clear interface, consistency, attractiveness, information accuracy, information } \\
\text { completeness, perceived security, perceived privacy has positive impact on the user inten- } \\
\text { tion to adopt smart home technology. }\end{array}$ & $\begin{array}{l}\text { Partly Ac- } \\
\text { cepted }\end{array}$ \\
\hline
\end{tabular}


Clear interface for this study has a significant effect, which means provide an interface with the elements are placed with nice and easy to allocate each element. Consistency interface of the system also considers an important factor that will influence the intention of Malaysian householders to adopt the smart home system. For the attractiveness has a significant influence on intention to adopt smart home in Malaysia, this is because the smart home system is used for public individuals, the attractive interface is important to get the attraction of the user.

The information accuracy has a significant effect on the intention to adopt smart home, this is because the smart home system should display accurate and correct information on the screen which same as the value stored in the database. Besides that smart home system can be connected through the device from long distance, accurate information is very important for the user to monitor and operate their home environment and home appliances such as a fan.

The perceived security also is one of the most important factors that influence the intention of Malaysian householders to adopt the smart home system. The perceived security refers to the perception of consumer's transmission data are protected from unauthorized access from third party [31]. The security threats easily occur through network level (server), communication channel or computer (client). It is important to the user because the smart home system is transmitting the information and data over the network. It means that, there is probability the system hacked by others. Also, the privacy information must be protected by smart home system and guarantee that wouldn't leak out the privacy information of the user to the third party.

\section{Conclusion, Limitations and Further Research}

Both academics and practitioners can benefit from the results presented in this study. For the academics, the paper proposed a conceptual model in the context of system technology focus for adoption smart home in Malaysia. For the practitioners, according to the results, clear interface, consistency interface, attractiveness, information accuracy, perceived security and perceived privacy were the important factors that influenced the Malaysian intention to adopt the smart home. The clear interface is the most dominants compare with others and security is the following because this two is the highest mean value, which can refer to the descriptive analysis. Therefore, the developers should design a more user-friendly system with a clear, simple, consistent and attractive interface. Besides that, the smart home system must also guarantee the information is accurate and correct as of the display value same as what store in the database. The smart home system should emphasize on its security and privacy information protection from unauthorized third party access it.

This research was conducted to examine the factors influencing the Malaysian intention to adopt smart homes. Due to the limited numbers of the sample size, it might not be correct representatives the real situation in Malaysia. There are some recommendations for future studies. 
First, the study should increase the respondents which can be more accurate representatives in Malaysia. Although the sample size between 30 and 500 is appropriate for research, but the more data collected the more accurate it can be representatives.

Second, the model use in this study is focus on system perspective to investigate the intention to adopt smart home. It can imply that there may be other factors which in non-system perspective variable affecting the intention to adopt smart home. Therefore, the future study can include others non-system perspective variable to investigate the intention of Malaysian to adopt smart home.

\section{References}

[1] N. Balta-Ozkan, R. Davidson, M. Bicket, and L. Whitmarsh, "Social barriers to the adoption of smart homes", Energy Policy, vol. 63, pp. 363-374, 2013. https://doi.org/10.1016/j. enpol.2013.08.043

[2] H. Yang, H. Lee, and H. Zo, "User acceptance of smart home services: an extension of the theory of planned behavior", Industrial Management \& Data Systems, vol. 117, no. 1, pp. 68-89, 2017. https://doi.org/10.1108/IMDS-01-2016-0017

[3] D. Bregman, and A. Korman, "A Universal Implementation Model for the Smart Home", International Journal of Smart Home, vol. 3, no. 3, pp. 15- 30, 2009.

[4] B. Brumitt, B. Meyers, J. Krumm, A. Kern, and S. Shafer, "Easy Living: Technologies for Intelligent Environments", Springer Berlin / Heidelberg, 2002. https://doi.org/10.1007/3-5 $\underline{\text { 40-39959-3_2 }}$

[5] J. Y, Kim, Y. Park, and J. Choi, "A study on the adoption of IoT smart home service: using Value-based Adoption Model”, Total Quality Management and Business Excellence, vol. 28, pp. 1149-1165, 2017. https://doi.org/10.1080/14783363.2017.1310708

[6] G. M. Salimon, H. A. Goronduste, and H. Abdullah, "User adoption of Smart Homes Technology in Malaysia: Integration TAM 3, TPB, UTAUT 2 and extension of their constructs for a better prediction", IOSR Journal of Business and Management, vol. 2, no. 4, pp. 60-69, 2018.

[7] H. Yang, and H. Lee, "Exploring user acceptance of streaming media devices: an extended perspective of flow theory", Information Systems and e-Business Management, vol. 16, pp. 1-27, 2018. https://doi.org/10.1007/s10257-017-0339-x

[8] Statista, "Smart Home in United States", Retrieved from Statista: https://www.statista.com/outlook/279/109/smart-home/united-states, 2017 https://doi.org/ 10.5260/cca. 199318

[9] T-Y, Shih, "Determinates of consumer adoption attitudes: an empirical study of smart home services", International Journal of E-Adoption, vol. 5, no. 2, pp. 40-56, 2013. https:// doi.org/10.4018/jea.2013040104

[10] J. Wong, and J. Leung, "Modelling factors influencing the adoption of smart-home technologies", Facilities, vol. 34, no. 13/14, pp. 906-923, 2016. https://doi.org/10.1108/F-052016-0048

[11] T-H-L. Nguyen, M-H. Duong, H-D, Nguyen, D-H. Vo, D-P-T. Vu, and H-S. Le, "Key Determinants for Users Intention to Use Smart home Devices in Vietnam", Journal of Multimedia Information System, vol. 5, no. 4, pp. 283-290, 2018. http://dx.doi.org/10.9717/ JMIS.2018.5.4.283 
[12] L. Liu , E. Stroulia , I. Nikolaidis , A. Miguel-Cruz, A. Rios Rincon, "Smart homes and home health monitoring technologies for older adults: a systematic review", Int. J. Med. Inform. vol. 91, pp. 44-59, 2016. https://doi.org/10.1016/j.ijmedinf.2016.04.007

[13] F. D. Davis, "Perceived usefulness, perceived ease of use, and user acceptance of information technology", MIS quarterly, vol. 13, no. 3, pp. 319-340, 1989. https://www.jstor.org/ stable/249008 https://doi.org/10.2307/249008

[14] J. V. Chen, D. C. Yen, and K. Chen, "The acceptance and diffusion of the innovative smart phone use: a case study of a delivery service company in logistics", Information Management, vol. 46, no. 4, pp. 241-248, 2009. https://doi.org/10.1016/j.im.2009.03.001

[15] W. Lai, "Exploring Use Intention of a Smart Bike-Sharing System-Extending Technology Acceptance Model with Trust”. In: Zhang Z., Shen Z., Zhang J., Zhang R. (eds) LISS 2014. Springer, Berlin, Heidelberg, 2015. https://doi.org/10.1007/978-3-662-43871-8 230

[16] M. Hubert, M. Blut, C. Brock, W. R Zhang, V. Koch and R. Riedl, "The influence of acceptance and adoption drivers on smart home usage", European Journal of Marketing, vol. 53, no. 6, pp. 1073-1098, 2019. https://doi.org/10.1108/EJM-12-2016-0794

[17] A. Susanto, H. Lee, H. Zo, and A. P. Ciganek, "User acceptance of internet banking in Indonesia: initial trust formation", Information Development, vol. 29, no. 4, pp. 309-322, 2013. https://doi.org/10.1177/0266666912467449

[18] M. Nikola, and A. Granic, "Technology acceptance model: a literature review from 1986 to 2013", Universal Access in the Information Society, vol. 14, no. 1, pp. 81-95, 2015. https://doi.org/10.1007/s10209-014-0348-1

[19] E. K. Nkonko, N. Chiliya, T. Chuchu, and T. Ndoro, "An Investigation into the Factors Influencing the Purchase Intentions of Smart Wearable Technology by Students", International Journal of Interactive Mobile Technologies (iJIM), vol. 13. No. 5, 15-29, 2019. https ://doi.org/10.3991/ijim.v13i05.10255

[20] S. Papadakis, "Evaluating pre-service teachers' acceptance of mobile devices with regards to their age and gender: a case study in Greece", International Journal of Mobile Learning and Organisation, vol. 12, no. 4, pp. 336-352, 2018. https://doi.org/10.1504/IJMLO.2018.0 $\underline{95130}$

[21] M. Kalogiannakis, and S. Papadakis, "Evaluating pre-service kindergarten teachers' intention to adopt and use tablets into teaching practice for natural sciences", International Journal of Mobile Learning and Organisation, vol. 13, no. 1, pp. 113-127, 2019.

[22] Usability.gov, User Interface Design Basics. Retrieved from Usability.gov: https://www.usability.gov/what-and-why/user-interface-design.html https://doi.org/10.10 07/978-3-642-76283-3_12

[23] I. M. Eid, "Determinants of e-commerce customer satisfaction, trust, and loyalty in Saudi Arabia", Journal of electronic commerce research, vol. 12, no. 1, pp. 78-93, 2011.

[24] E. Park, S. Kim, and Y. Kim, "Smart home services as the next mainstream of the ICT industry: determinants of the adoption of smart home services", University Access Information Society, vol. 17, pp. 175-190, 2018. https://doi.org/10.1007/s10209-017-0533-0

[25] A. Burns, and R. Bush, "Marketing research: Online research application", New Jersey: Prentice Hall, 2003.

[26] R. Atkinson, and J. Flint J., "Accessing hidden and hard-to-reach populations: Snowball research strategies", Social research update, vol. 33, no. 1, pp. 1-4, 2001.

[27] J. F. Hair, R. E. Anderson, R. L. Tatham, and C. William, "Multivariate data analysis", 5th. NY: Prentice Hall International, 1998.

[28] J. F. Hair, M. Sarstedt, L. Hopkins, and V. Kuppelwieser, "Partial least squares structural equation modeling (PLS-SEM) An emerging tool in business research", European Business Review, vol. 26, no. 2, pp. 106-121, 2014. https://doi.org/10.1108/EBR-10-2013-0128 
[29] J. Pallant, “SPSS Survival Manual”, McGraw-Hill Education (UK), 2013.

[30] J. Cohen, P. Cohen, S. G. West, and L. S. Aiken, “Applied multiple regression/correlation analysis for the behavioral sciences", Routledge, 2013.

[31] S. Salloum, M. Al-Emran, R. Khalaf, M. Habes, and K. Shaalan, “An Innovative Study of E-Payment Systems Adoption in Higher Education: Theoretical Constructs and Empirical Analysis", Journal of Interactive Mobile Technologies (iJIM), vol. 13, no. 6, pp. 68-83, 2019. https://doi.org/10.3991/ijim.v13i06.9875

\section{Authors}

Ng Tee Wei, Master from the school of computer sciences, Universiti Sains Malaysia (USM), his field is Business informatics.

Dr. Ahmad Suhaimi Baharudin, is an Associate Professor at the School of Computer Sciences, Universiti Sains Malaysia (USM). His Ph.D. and MBA degrees earned from the School of Management, Universiti Sains Malaysia (USM). His Bachelor's degree in Computer Science was earned from Indiana State University, USA. He is a Chartered Secretary and Chartered Governance Professional (ACIS (CS) (CGP) (UK). $\mathrm{He}$ is interested in Management of Information Systems (MIS), Technopreneurship, Quantitative Analysis and Research Methodology. He has several journal articles and conference presentations to his record.

Dr. Lubna A. Hussein is currently a Post-Doctoral at the School of Distance Education, Universiti Sains Malaysia (USM). Her PhD degree earned from the school of Computer Sciences in the field of Management Information Systems, Universiti Sains Malaysia (USM). Her area of research interested in business IT and Technology Adoption.

Dr. Mohd Faiz Hilmi is currently attached to the School of Distance Education, Universiti Sains, Malaysia. He received his DBA from Universiti Sains Malaysia, MBA from Universiti Utara, Malaysia and a B.A. degree from Washington State University. Prior to joining Universiti, Sains Malaysia, he had 11 years of multifunctional accomplishments including as IT engineer, IT project/support coordinator, product data specialist and configuration manager in various multinationals corporations. Companies and organizations he has been working with include MCMS, Advanced Micro Devices, Celestica, Intel and Motorola. His areas of research interest include Innovation and Technology Management.

Article submitted 2019-06-21. Resubmitted 2019-08-06. Final acceptance 2019-08-10. Final version published as submitted by the authors. 